\title{
THE ROLE OF OXYGEN IN THE REGULATION OF ERYTHROPOIESIS. DEPRESSION OF THE RATE OF DELIVERY OF NEW RED CELLS TO THE BLOOD BY HIGH CONCENTRATIONS OF INSPIRED OXYGEN ${ }^{1,2}$
}

\author{
BY JOHN C. TINSLEY, JR.,3 CARL V. MOORE, REUBENIA DUBACH, VIRGINIA \\ MINNICH, AND MOISES GRINSTEIN \\ (From the Department of Internal Medicine, Washington University School of Medicine and \\ the Barnes Hospital, St. Louis)
}

(Received for publication July 2, 1949)

Oxygen tension of the environment is regarded as one of the principal regulators of the rate of erythropoiesis. This concept is based largely on the fact that stimulation of red blood cell formation regularly occurs at high altitudes, or under conditions of decreased oxygen tension. Evidence that the converse is true, that high tensions of oxygen can decrease erythrocyte formation, is more fragmentary. A few experiments have demonstrated that animals become anemic within a few weeks when placed in atmospheres containing 60 per cent or more of oxygen at normal barometric pressure (1-3). Early attempts to demonstrate a similar depressant effect in human subjects were unsuccessful, usually because the concentrations of oxygen were not sufficiently high, or because the observations were continued for only short periods of time $(4,5)$. Since the human red cell normally survives in the circulation for approximately 120 days, it is evident that special technics must be used, or the exposure to high concentrations of oxygen must be continued for weeks if an unequivocal drop in the red blood cell level of a normal subject is to be produced.

Reinhard and his associates (6) circumvented these difficulties by using patients with sickle cell anemia as subjects for their studies. Because the survival time of the erythrocyte in sickle cell anemia is short $(7,8)$, and the reticulocyte level is high, it was possible to show that the continuous administration of 80 per cent oxygen by face

1 These studies were supported in part by a research grant from the Division of Research Grants and Fellowships of the National Institutes of Health, U. S. Public Health Service, and in part by a grant from $\mathrm{Mr}$. S. Averbuch.

2 The oxygen used during this investigation was generously provided by the Linde Oxygen Company.

3 Senior Research Fellow, U. S. Public Health Service. mask for eight to 20 days caused a dramatic fall in both the reticulocytes and the red cells. While this evidence for the depression of erythrocytogenesis seemed definite, it was necessary to demonstrate that the phenomenon was a general one, and not limited to sickle cell anemia. The data accumulated in the present study show that depression of erythropoiesis may also be produced by continuous inhalation of high oxygen concentrations in patients with congenital hemolytic anemia, in patients with pernicious anemia in relapse during response to specific therapy, and in persons with a normal hematopoietic equilibrium.

Oxygen was given continuously through a meter face mask. A nasal mask was substituted during meals, but at no other times. Determinations of arterial oxygen saturation and of alveolar oxygen were made at intervals as a check on the effectiveness of oxygen administration. No significant change occurred in plasma $\mathrm{pH}$ or in carbon dioxide content of the blood.

\section{MATERIALS, METHODS, AND BASIC EXPERI- MENTAL CONDITIONS}

Red and white blood cell counts were made on capillary and venous blood with diluting pipettes and hemocytometers standardized by the U. S. Bureau of Standards. Hemoglobin was determined photoelectrically as oxyhemoglobin (9). Hematocrits and corpuscular constants were obtained by Wintrobe's method $(10,11)$. Differential white blood cell counts were done with supravital staining. Dameshek's technic was used for counting reticulocytes and blood platelets (12). Reticulocytes are recorded in terms of number per $\mathrm{cu}$. $\mathrm{mm}$. with percentage levels given in parentheses; each value represents a determination on 2,000 to 6,000 red cells, except in Case 8 in which only 1,000 cells were counted routinely.

Fractional serum bilirubin was determined by the method of Malloy and Evelyn (13) as modified by Ducci and Watson (14). Daily fecal and urine urobilinogen output was followed by the method of Watson (15), 
with attention to the studies of Kelly et al. (16). Plasma and serum irons were studied by two methods, that of Moore and his associates (17) in some subjects and that of Barkan and Walker (18) as modified by Grinstein et al. (19) in others. Technics used in determining radioactive iron in blood have been described in a previous publication from this laboratory (20). Studies of plasma $\mathrm{pH}$ were made with the technic of Cullen (21), adapted to the colorimeter by Evelyn and Malloy (22). The method of Grinstein and Wintrobe (23) was used for determination of the free erythrocyte protoporphyrin (E.P.).

Samples of alveolar air were obtained as described by Henderson and Morriss (24), kept over saturated calcium chloride solution in a Hempel pipette and analyzed for oxygen, carbon dioxide and nitrogen as described by Van Slyke and Sendroy (25). Oxygen and carbon dioxide contents and capacities of arterial and venous blood were determined on $1 \mathrm{cc}$. samples by the method of Van Slyke and Neill (26 a, b).

Human subjects studied were patients in the Barnes Hospital who volunteered for the procedures. Oxygen was administered through an oronasal meter mask, the concentration of oxygen and the humidification being regulated by the "injector" as described by Barach and Eckman (27).4 Except for periods of 30 minutes or less at meal times when the patients wore nasal masks, the oxygen was given continuously by full-face mask for the prescribed number of days. In all cases, carefully instructed and supervised practical nurses were at the bedside for at least 12 hours at night and usually for 24 hours a day, solely to be sure that the masks were fitted and working properly at all times.

\section{HEMOLYTIC ANEMIAS}

Reinhard et al. (6) emphasized that patients with chronic hemolytic anemias offer the following advantages as subjects for a study of the effects of an agent which depresses the rate of erythrocytogenesis : 1) the life span of the average red cell in the circulation is much shorter than normal; therefore, any decrease in the rate of delivery of new cells is followed more quickly by a fall in the red cell count, hemoglobin and hematocrit; 2) reticulocytes are greatly increased in number so that a wider range is available through which a decrease may be demonstrated; 3 ) if the rate of red cell destruction is assessed continuously by determination of the daily total urobilinogen excretion and is found to be reasonably stable, consistent and progressive changes in daily red cell counts reflect changes in the rate of formation and delivery of the red cells to the circulation. The only pa-

4 These masks are designed to prevent rebreathing from the reservoir bag. tients with chronic hemolytic anemias who both satisfied these conditions and were available as subjects for these studies were those with sickle cell anemia and congenital hemolytic anemia. Sickle cell anemia was included because it was considered desirable to confirm the previous observations (6) as a part of this more comprehensive study.

\section{(A) Sickle cell anemia}

After a control period of three days, the first patient, L. M. B., was given 80 per cent oxygen continuously by face mask for 14 days. The data obtained are charted in Figure 1. Figures tabulated beneath the graphs show that during the oxygen period: 1) alveolar $\mathrm{O}_{2}$ tension was found to vary from 415 to $528 \mathrm{~mm}$. $\mathrm{Hg} ; 2$ ) alveolar $\mathrm{CO}_{2}$ tension decreased slightly; 3) arterial $\mathrm{O}_{2}$ saturation was increased above 100 per cent; and 4) the total serum bilirubin varied irregularly.

On the fourth day of oxygen administration, the reticulocytes began to decrease from their average control level of 475,000 per cu. mm. (15.0 per cent) and dropped to less than 60,000 per cu. $\mathrm{mm}$. (2.6 per cent) on the eighth day. By the 14th day, the total red cell count had fallen from about 3.14 to 2.2 million per cu. $\mathrm{mm}$., the hemoglobin from 9.4 to $6.5 \mathrm{Gm}$. per $100 \mathrm{cc}$., and the hematocrit from 28 to 20.5 per cent. The oxygen mask was then removed. Two days thereafter, the reticulocytes began to increase, reached a peak of $1,520,000$ per cu. mm. (64.9 per cent) on the 12th day, and then gradually returned to a level near that of the control period. The red blood cells, hemoglobin, and hematocrit continued to fall for the first two days of the post-oxygen period, reaching low values of 1.87 million per cu. mm., $5.3 \mathrm{Gm}$. per cent, and 16 per cent respectively; all three values then rose steadily until control levels were attained. A striking outpouring of normoblasts into the peripheral blood occurred between the fifth and the eighth post-oxygen days.

The total leucocyte count showed no definite changes which could be correlated with the oxygen administration, but a transient granulocytic leucocytosis of 23,800 per cu. mm. developed after the mask was removed. Platelets varied irregularly between 585,000 and $1,260,000$ per cu. mm. during the period of study.

In an attempt to obtain additional evidence for 
Effect of Continuous Inhalation of $80 \%$ Oxygen on the Blood of a Patient With Sickle Cell Anemia

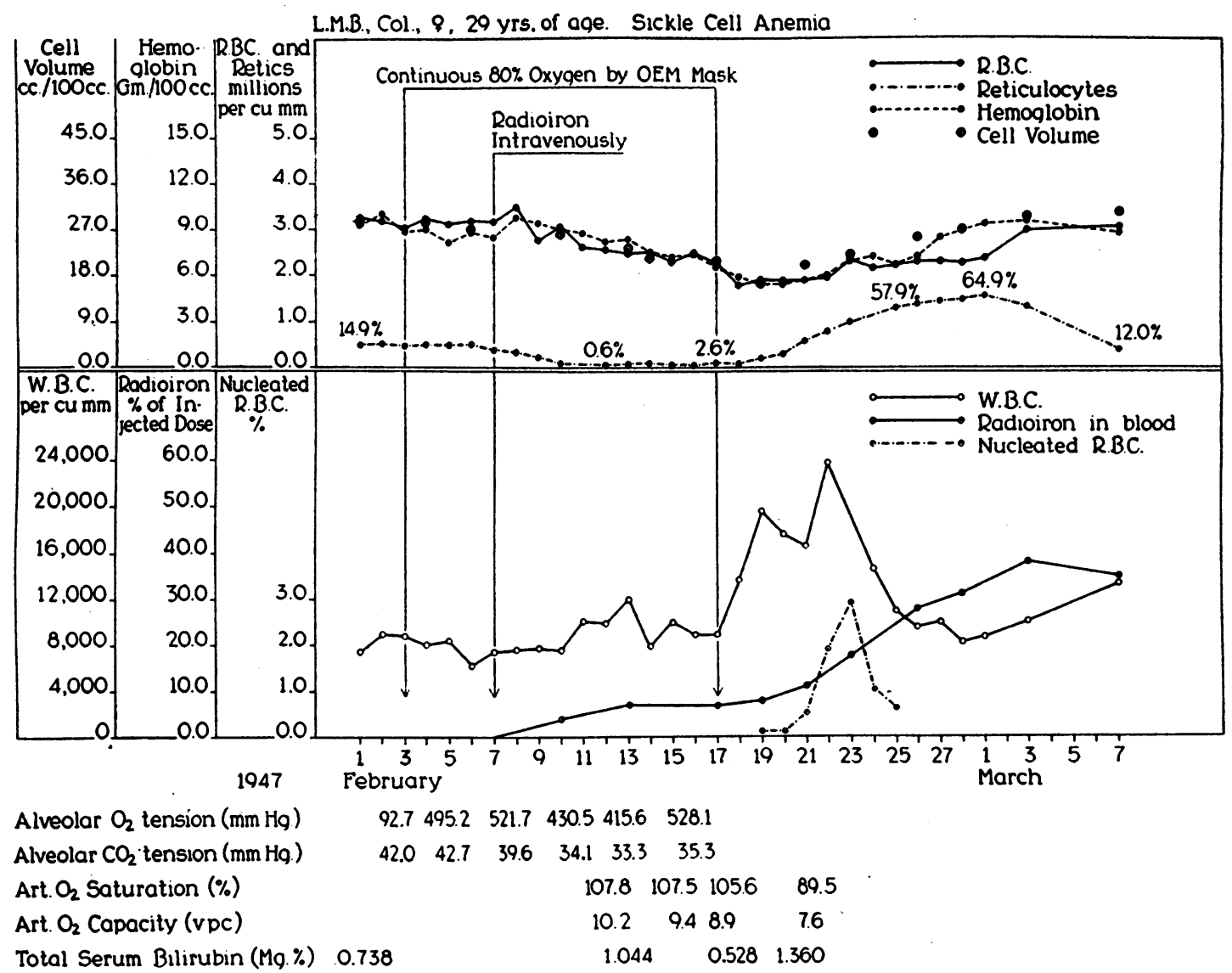

Frg. 1

the depressant effect of oxygen on erythropoiesis, a study was made of the rate at which intravenously injected radioactive iron was utilized for hemoglobin synthesis (28). Fifteen $\mathrm{mg}$. of $\mathrm{Fe}^{58}$ as ferrous ascorbate (616,000 counts per minute) were given intravenously on the fourth day of the oxygen period. During the remaining 10 days of oxygen administration, only 7.8 per cent of the injected radioiron appeared in circulating hemoglobin; but after oxygen was discontinued, the radioiron utilization curve rose rather sharply to 27.6 per cent within nine days (Figure 1).

The shape of the radioiron utilization curve plus the changes both in reticulocytes and in the other red corpuscular values are all consistent with the interpretation that: 1 ) red cells were delivered to the circulation at a slower rate while 80 per cent oxygen was being administered; and 2) a marked stimulation of erythrocytogenesis occurred when the patient was returned to room air.
The second patient, G. P., was given 50 per cent oxygen continuously for 11 days (Figure 2 ). This smaller concentration was used: 1) to obtain a rough estimate of the concentration required to produce the depressant effect ; and 2) to determine whether the hematologic changes could be induced when the amount of oxygen was low enough to avoid any recognizable manifestations of oxygen toxicity. Determinations of alveolar and blood gases were not made but the administration of oxygen was supervised 24 hours a day by special practical nurses who had no responsibilities other than to this one patient. Since alveolar oxygen had been observed to fall while the nasal mask was used during meals, the oxygen flow was increased to 100 per cent during those periods (approximately 20 minutes three times a day).

The decrease in reticulocytes and red blood cells during the oxygen period, followed by their return to control levels after the mask was removed, 
was quite similar to that obtained with high concentrations of oxygen in the previous patient and in the studies by Reinhard et al. (6). The postoxygen reticulocytosis was not as great and no normoblastic shower occurred, but there were no other differences.

Free erythrocyte protoporphyrin was measured in this patient to determine whether it would vary as the reticulocytes changed. No decrease was observed during the oxygen period, and although the level rose sharply after oxygen was discontinued, there was little direct correlation between the time of that rise and the reticulocytosis which followed several days later. The level of free erythrocyte protoporphyrin is influenced by the number of young erythrocytes in the circulation, by inflammation, by iron and pyridoxine deficiencies, and by other factors $(19,29)$; which of these was responsible for the changes observed in this case is not clear.

\section{(B) Congenital hemolytic anemia}

For the third study, a subject with congenital hemolytic icterus was selected (L. D., Figure 3). After a control period of four days, humidified pure (USP) oxygen was administered continuously for eight days. The alveolar oxygen tension rose from the pre-oxygen level of $92 \mathrm{~mm}$. of $\mathrm{Hg}$ to values above $600 \mathrm{~mm}$. of $\mathrm{Hg}$ on several examinations. The arterial oxygen saturation was in creased from 85 per cent ${ }^{5}$ to 97 and 102 per cent on two examinations; the oxygen saturation of blood from the antecubital veins was increased from 31 and 43 per cent without the oxygen to 61,73 , and 78 per cent during the oxygen period. The

5 Method of handling blood for oxygen capacity determinations on this patient resulted in erroneously high values, thus giving erroneously low values for oxygen saturations throughout. Since the method was used consistently, the changes in oxygen saturation are considered to be significant if not absolutely accurate.

\section{Effect of Continuous Inhalation of $50 \%$ axygen on Erythropoiesis}

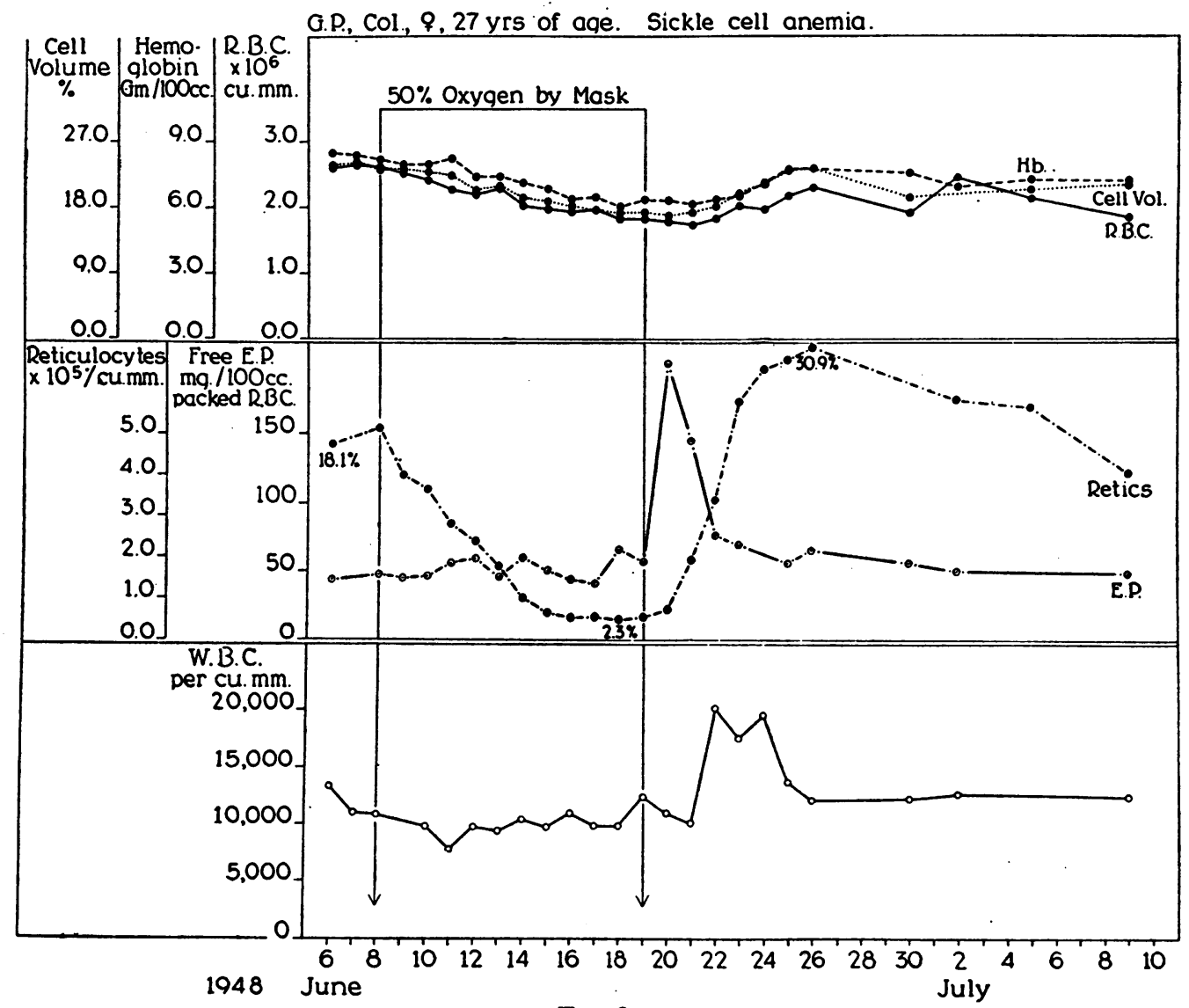

FrG. 2 
Effect of Continuous Inhalation of Oxygen in Patient with Congenital Hemolytic Anemia

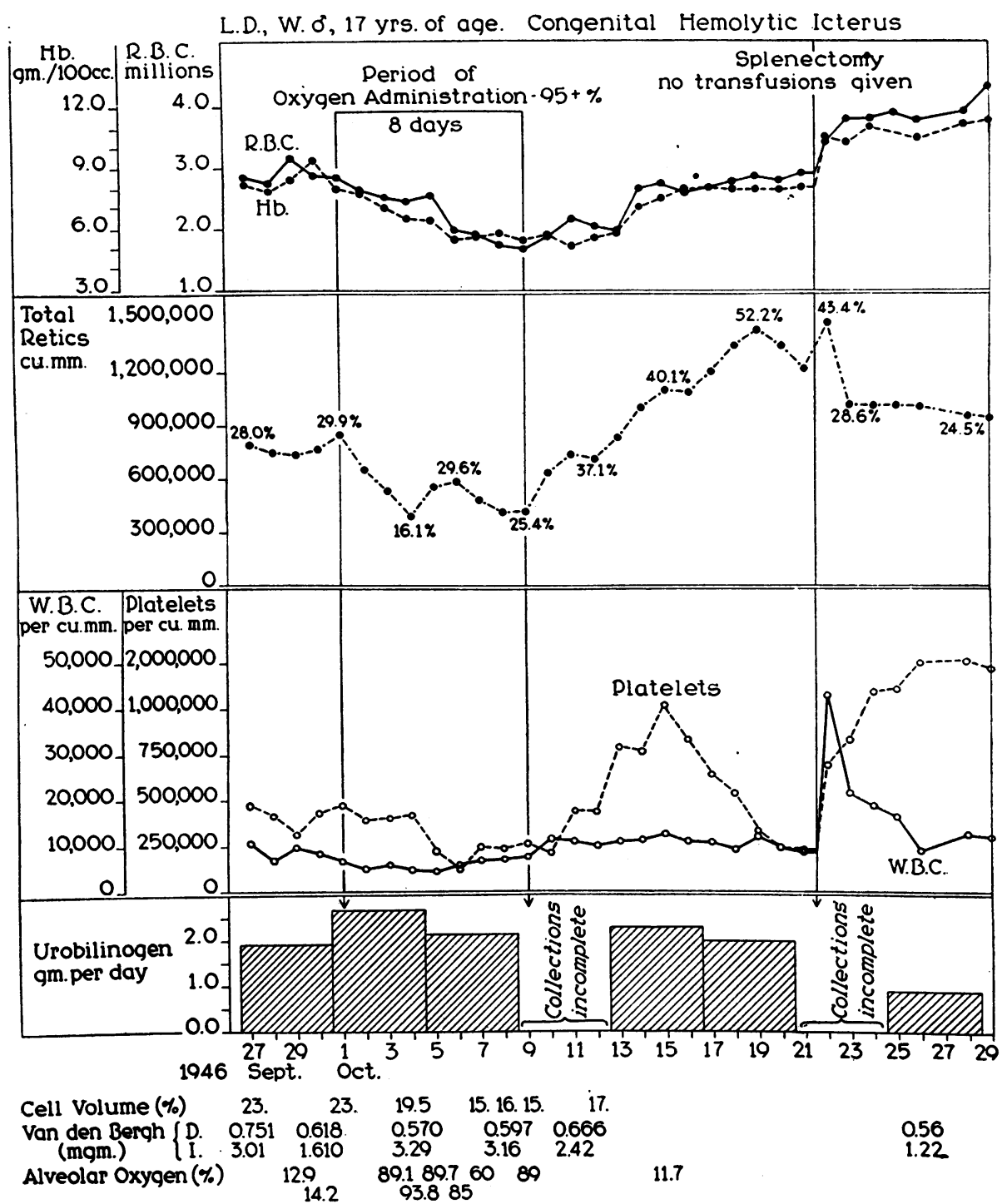

FIG. 3

carbon dioxide content of arterial blood was raised from the control value of 54 volumes per cent to 59.7 on the final day of oxygen administration and there was a parallel rise in the carbon dioxide content of venous blood from 56.5 to 61.4 volumes per cent. Both values returned to control levels after the oxygen was discontinued. Bone marrow, aspirated in the middle and at the end of the oxygen period, showed no evidence of erythroid hypoplasia.

During oxygen administration, the following changes in hematologic status occurred: 1) the red blood cells fell rapidly from the average control count of $2,880,000$ per cu. mm. to $1,640,000$ on the eighth day; 2) the hematocrit decreased from 23 to 15 per cent; 3 ) hemoglobin fell from 8.4 to $5.3 \mathrm{Gm}$. per cent; 4 ) the reticulocytes which averaged 780,000 per cu. $\mathrm{mm}$. (27.1 per cent) fell to 390,000 (16.1 per cent) on the third day, rose to 583,000 ( 29.6 per cent) by the fifth day, and gradually decreased to reach 417,000 per cu. $\mathrm{mm}$. (25.4 per cent) on the eighth day; 5) the platelets also diminished in number from the control average of 414,000 per $\mathrm{cu}$. $\mathrm{mm}$. to 118,000 on the 
fifth day, to remain below 254,000 during the oxygen period ; 6 ) leucocytes decreased from the average of 8,320 per cu. $\mathrm{mm}$. to 4,100 on the fourth day, after which they rose steadily to 7,600 by the eighth day; 7) during the first half of the oxygen period the average daily urobilinogen excretion increased from the pre-oxygen figure of $1,830 \mathrm{mg}$. to 2,650 and then diminished to 2,150 during the second half ; 8 ) the few determinations of total serum bilirubin varied between 2.2 and $3.9 \mathrm{mg}$. per cent without definite relation to the controlled conditions ; 9) the serum iron which averaged 148 $\mu \mathrm{g}$. per $100 \mathrm{cc}$. during the control period was found to be $89 \mu \mathrm{g}$. on the third and 115 on the sixth day.

After administration of 100 per cent oxygen was stopped, the following hematologic changes were noted; 1) a marked reticulocytosis occurred, reaching a peak of $1,480,000$ per cu. mm. (52.2 per cent) on the tenth day ; 2) the red cells, hematocrit and hemoglobin rose rapidly to reach the preoxygen range by the tenth day; 3 ) the platelets increased sharply to $1,050,000$ per cu. $\mathrm{mm}$. on the sixth day; 4) the white cells showed no striking variation; 5) the urobilinogen output during the four days immediately following the end of the oxygen period could not be determined because one fecal specimen was lost, but the daily average for the next four days was $2,256 \mathrm{mg}$.; and 6) the serum iron varied between 80 and $130 \mu \mathrm{g}$. on four examinations during the 11 days following the cessation of oxygen administration. No significant change occurred in the osmotic fragility of the red cells during any of the phases of the whole period of observation.

This study was complicated by two factors. The greater urobilinogen excretion obtained during the first few days of oxygen therapy probably resulted from a transient increase in erythrocyte destruction. Such an accelerated rate of hemolysis may have been responsible for the "hump" in the reticulocyte curve, and may have exaggerated the red cell fall which oxygen alone would have produced. Secondly, the oxygen period had to be terminated at the end of eight days because the patient developed a severe bronchitis and fever, both of which were probably caused by the high oxygen concentration being given. Other manifestations of oxygen toxicity in this boy are described in the case summary, at the end of this paper. It is realized that he would not have been able to tolerate pure oxygen longer than for a short period if there had not been interruptions with talking, at meals, and for adjustment of the mask (30).

In congenital hemolytic anemia, as in sickle cell anemia, therefore, high concentrations of inspired oxygen caused a decrease in red blood cell values and in the total reticulocyte count. After oxygen was discontinued, there was a striking release from the erythroid depression: reticulocytes increased to very high levels and the erythrocyte count returned to control values. The reticulocytes did not fall to the very low levels observed repeatedly in patients with sickle cell anemia, but the directional changes were entirely similar.

\section{PERNICIOUS ANEMIA}

In patients with pernicious anemia, there is an excellent opportunity to demonstrate the depressant effects of high oxygen concentrations on red cell formation. The hematologic response induced by adequate specific therapy is both characteristic and highly predictable (31-34). Any significant depression of the response to liver extract produced by oxygen inhalation, therefore, should be detectable. If inhalation of oxygen should fail to inhibit completely the expected reticulocytosis, it might at least cause the response to be submaximal. In the latter instance the principle of the double reticulocyte curve would apply (35-37) and a second rise might occur when oxygen was discontinued.

After a control period of four days, the first patient with untreated pernicious anemia (Case 4, E. B., Figure 4, upper graph) was given 80 per cent oxygen continuously for 11 days. During this time, the alveolar oxygen tension ranged between 390 and $468 \mathrm{~mm}$. Hg, and the arterial oxygen saturation was found on two occasions to be 106 and 104.5 per cent. Values for the arterial $\mathrm{CO}_{2}$ content at the beginning and at the end of the 11 days were 51.3 and 53.5 volumes per cent, respectively. After 48 hours of 80 per cent oxygen, 20 USP units of liver extract were injected intramuscularly. The reticulocytes began to increase three days later, reached a peak of 283,000 per cu. $\mathrm{mm}$. (13.3 per cent) six days after the injection, and fell to 191,000 (7.5 per cent) by the time oxygen was discontinued and the second injection of liver extract was made. The second 
dose was also 20 USP units and was drawn from the same vial of extract used earlier. A second reticulocyte peak of 327,000 per cu. mm. (10.1 per cent) occurred on the ninth day thereafter. The red blood cell count, hemoglobin value and hematocrit showed no significant change until they began to rise after the oxygen period had been terminated and liver extract had been given the second time.

The number of reticulocytes per cu. $\mathrm{mm}$. was greater at the peak of the second response even though the percentage level was not quite as high.
Consequently, the second response was greater than the first. This result indicates that the 80 per cent oxygen had partially inhibited the therapeutic effectiveness of the first liver extract injected. This interpretation is based on the demonstration that if a single dose of liver extract causes a definite but suboptimal reticulocyte crisis, a second dose of the same amount will be followed by a second reticulocyte rise of smaller amplitude (37). That is what happened during a control study in which all conditions were similar except that room air was breathed throughout (Figure 4, lower graph).

\section{EFFECT OF OXYGEN ON THE HEMATOLOGIC RESPONSE TO LIVER EXTRACT IN DERNICIOUS ANEMIA}

E.B. W., o, 55 yrs. of age. Pernicious Anemia.

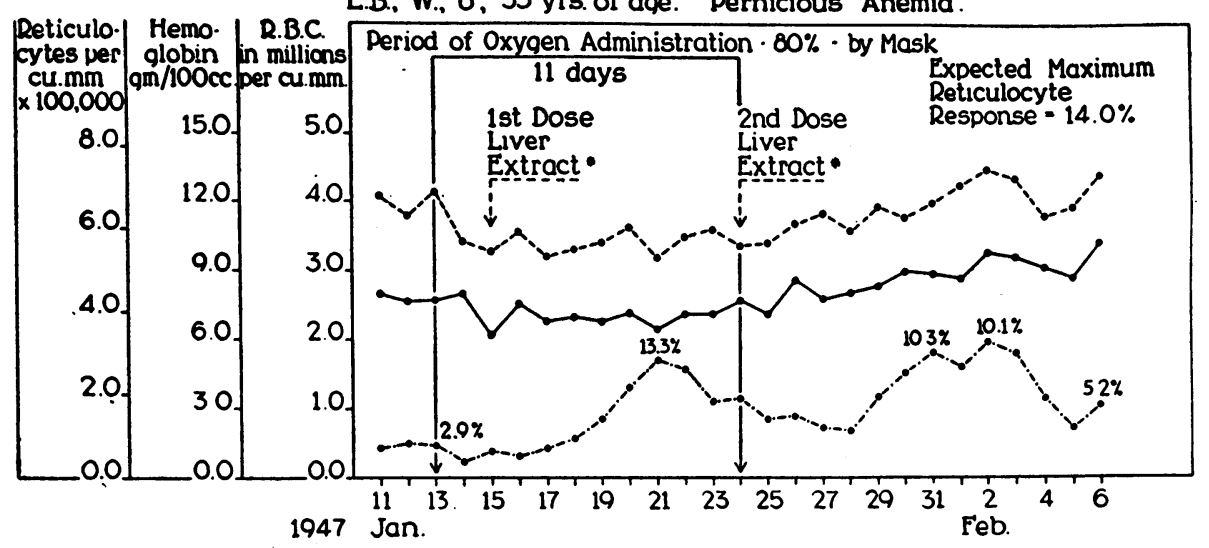

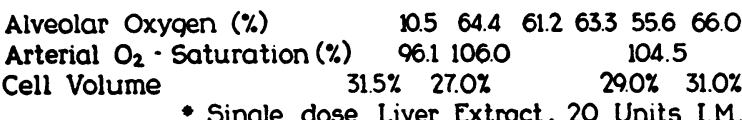

WITHOUT OXYGEN

LC., W. 9. 60 yrs. of age. Dernicious Anemia.

Response to two single doses of Liver Extract,

20 Units I.M. each dose, given nine days apart.

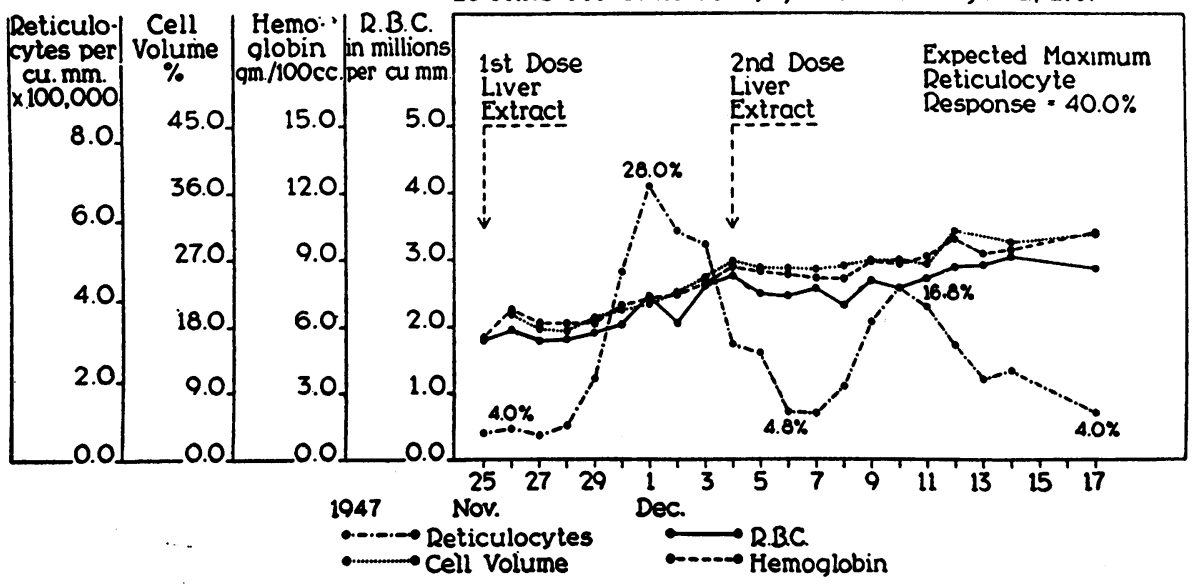

FIG. 4 


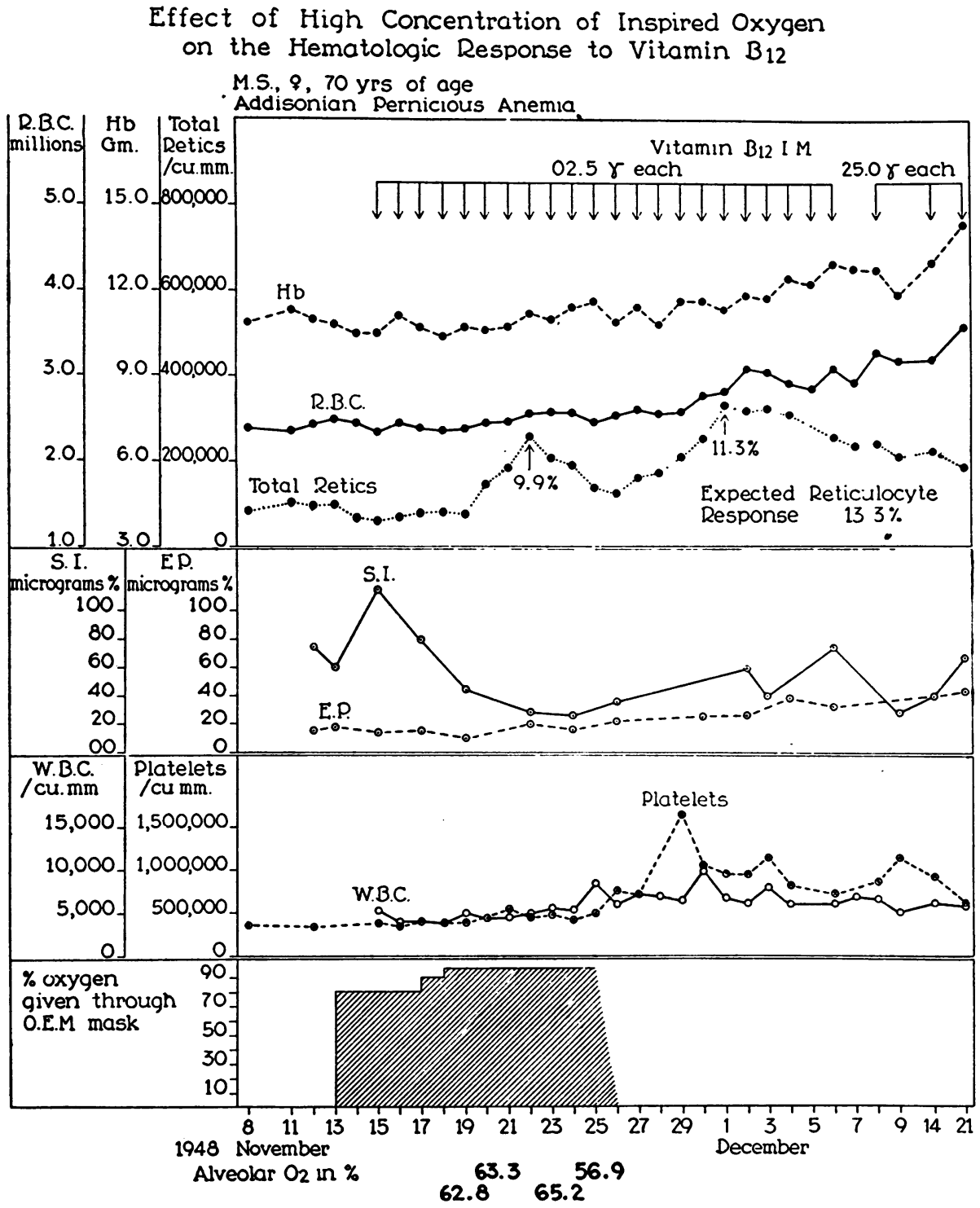

Fic. 5

When, however, the second reticulocyte response is greater (as it was in patient E. B.), it may be assumed that the first response was inhibited by some. factor not operating during the second response. While there is evidence, therefore, that oxygen partially depressed the effect of the initial injection of liver extract, it seemed best to avoid all uncertainty in the remaining studies and to inject relatively large doses of the anti-pernicious anemia principle daily.

The most striking result was obtained in M. S. (Case 5, Figure 5). After a control period of six days, this woman was given 80 per cent oxygen for four days; the injector was then set to deliver 95 per cent oxygen for an additional eight days. Practical nurses were in constant attendance at her bedside throughout this period. The patient found it difficult to follow instructions for the collection of alveolar air, but the four samples collected showed concentrations of 56.9 to 65.2 per cent oxygen and 5.4 to 6.2 per cent $\mathrm{CO}_{2}$. On the second day of the oxygen period and each day for the following three weeks, $2.5 \mu \mathrm{g}$. of crystalline Vitamin $\mathrm{B}_{12}{ }^{6}$ were injected intra-

- The authors are indebted to Dr. A. Gibson of Merck and Company for the supply of crystalline Vitamin $B_{12}$. 


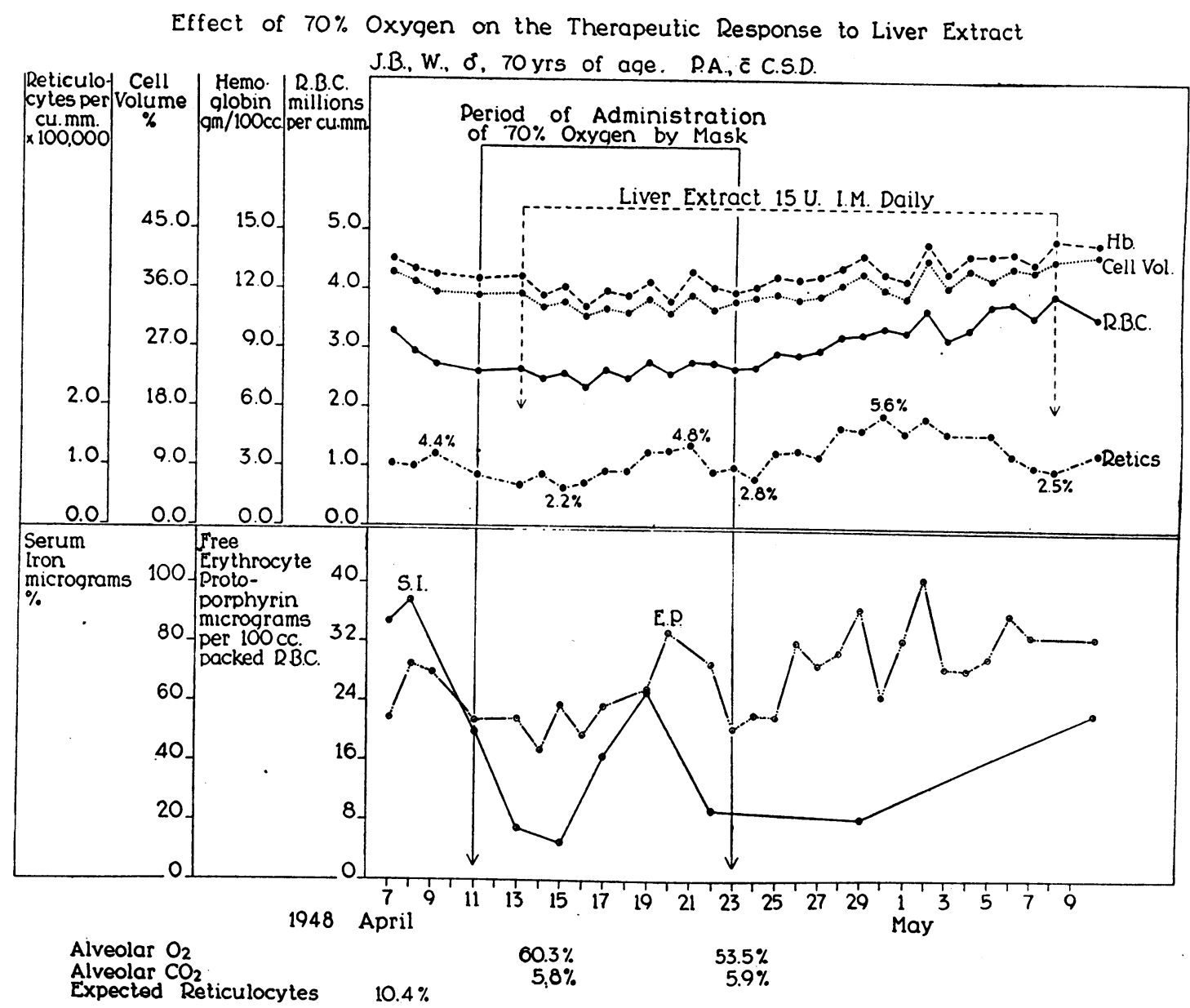

Fic. 6

muscularly (38). The reticulocytes began to rise on the fifth day of Vitamin $B_{12}$ therapy, attained a peak value of 252,000 per cu. mm. (9.9 per cent) on the seventh day and then fell to 121,000 . Within 48 hours after oxygen administration was discontinued, the reticulocytes began to climb again and this time reached a level of 324,000 (11.3 per cent) on the sixth post-oxygen day. The red blood cell and hemoglobin levels did not fall during the oxygen period, but showed their first rise on the fifth day after it had been terminated. The second reticulocyte response was developing at the time. It is interesting to observe that the leucocytosis and the sharp platelet rise which frequently accompany reticulocyte crises in pernicious anemia did not occur. The total white cell count varied through a narrow range during the whole period of observation; platelets increased abruptly after oxygen was discontinued.
Changes in serum iron were similar to those which usually follow antipernicious anemia therapy (39) but the rise in free erythrocyte protoporphyrin was unusually gradual.

In this patient, it seems reasonably certain that the high concentrations of oxygen she breathed caused a definite, though partial, inhibition of the hematologic response to Vitamin $B_{12}$. Two additional observations demonstrated the same effect. J. B. (Case 6, Figure 6) was given 70 per cent oxygen continuously for 12 days; 15 USP units of liver extract were injected daily. The first reticulocyte crisis was submaximal $(133,000$ per cu. mm.; 4.8 per cent) and was followed, after oxygen was discontinued, by a second greater rise (189,000 per cu. mm.; 5.6 per cent). Increases in free erythrocyte protoporphyrin were obtained at the time of each reticulocyte peak $(19,29)$. The final patient in this series, W. L. (Case 7, 
Figure 7), also received 70 per cent oxygen continuously, but for only 10 days. Daily doses of 10 USP units of liver extract were injected intramuscularly for 19 days beginning 24 hours after the oxygen mask was applied. The first reticulocyte rise was again submaximal (115,000 per cu. $\mathrm{mm}$.; 5.4 per cent) and was followed by a second, larger, post-oxygen increase (203,000 per cu. mm.; 7.5 per cent). Complicating factors were present in both of the last two cases (see Case Summaries at end of paper). J. B. may have had a prostatic carcinoma, but if so it was asymptomatic and caused no change in his clinical status during the period of observation. W. L. became retentive of urine on the day before oxygen administration was begun and constant drainage through a suprapubic cystotomy tube was instituted. His nonprotein nitrogen values were slightly elevated (see tabulated values on Figure 7). Attention should also be directed to the relatively small reticulocyte peaks. The preparations and the counts, however, were made with great care by the same observer during the time both patients were being studied.

When these studies were begun, it was thought that high concentrations of inspired oxygen might inhibit completely the hematologic response to antipernicious anemia therapy. That result was not obtained, but in each of the four subjects there was clear evidence that the administered oxygen did depress the response.

\section{NORMAL SUBJECTS}

Demonstration of the depressant effects of increased oxygen tension on erythrocytogenesis in normal subjects required the use of other technics. Since the normal survival of the human red cell in the circulation is about 120 days $(40,41)$, it would have been necessary to continue the administration of oxygen for a month or more in order to obtain an unequivocal drop in the total count, or to make certain that such a fall would not occur. Moreover, the normal reticulocyte level is so low that

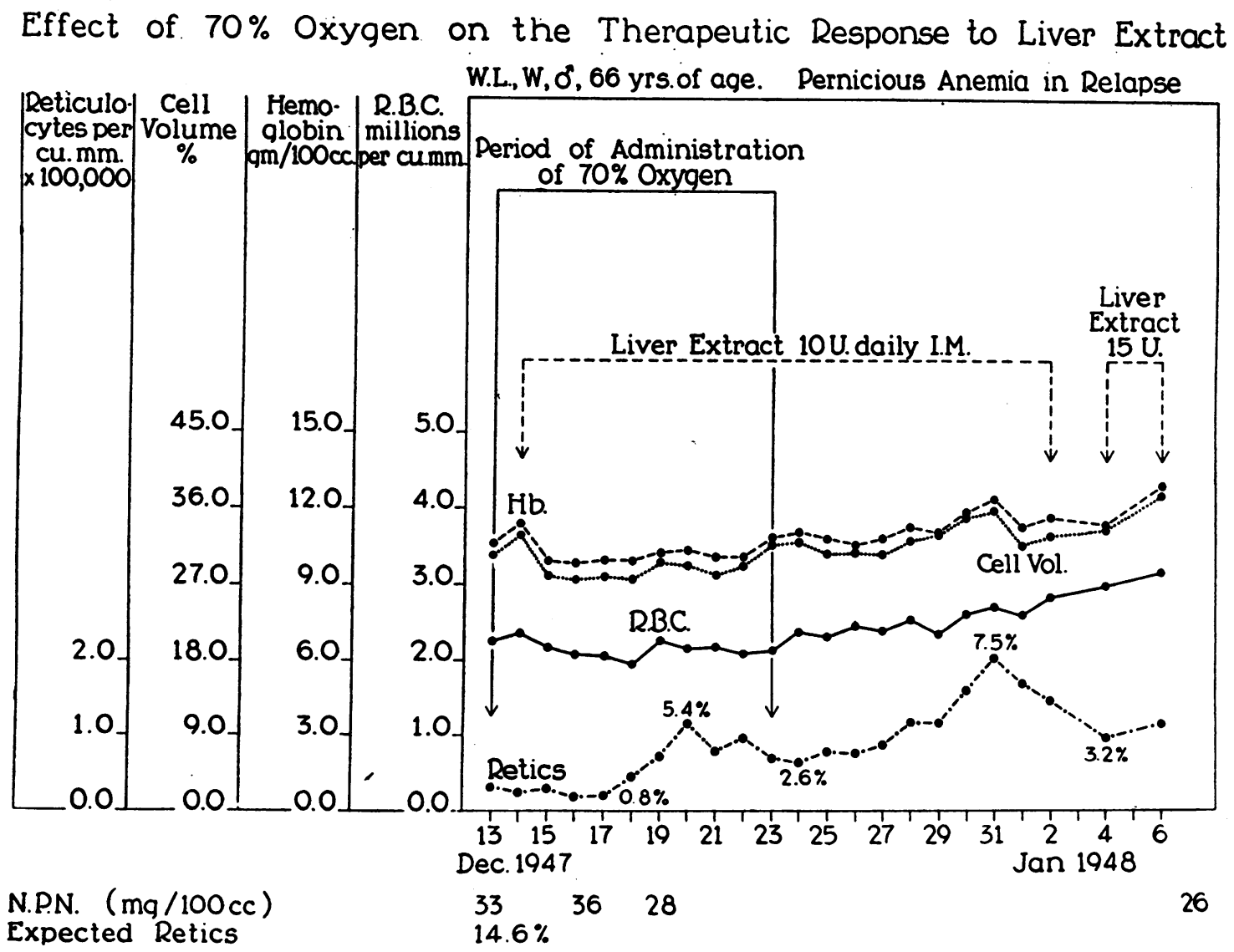

FIG. 7 
Effect of $70 \%$ Oxygen on Rate of Appearance of Radioiron in Blood after Intravenous Injection E.W., W., $\delta, 56$ yrs. of age. C.N.S. Syphilis.

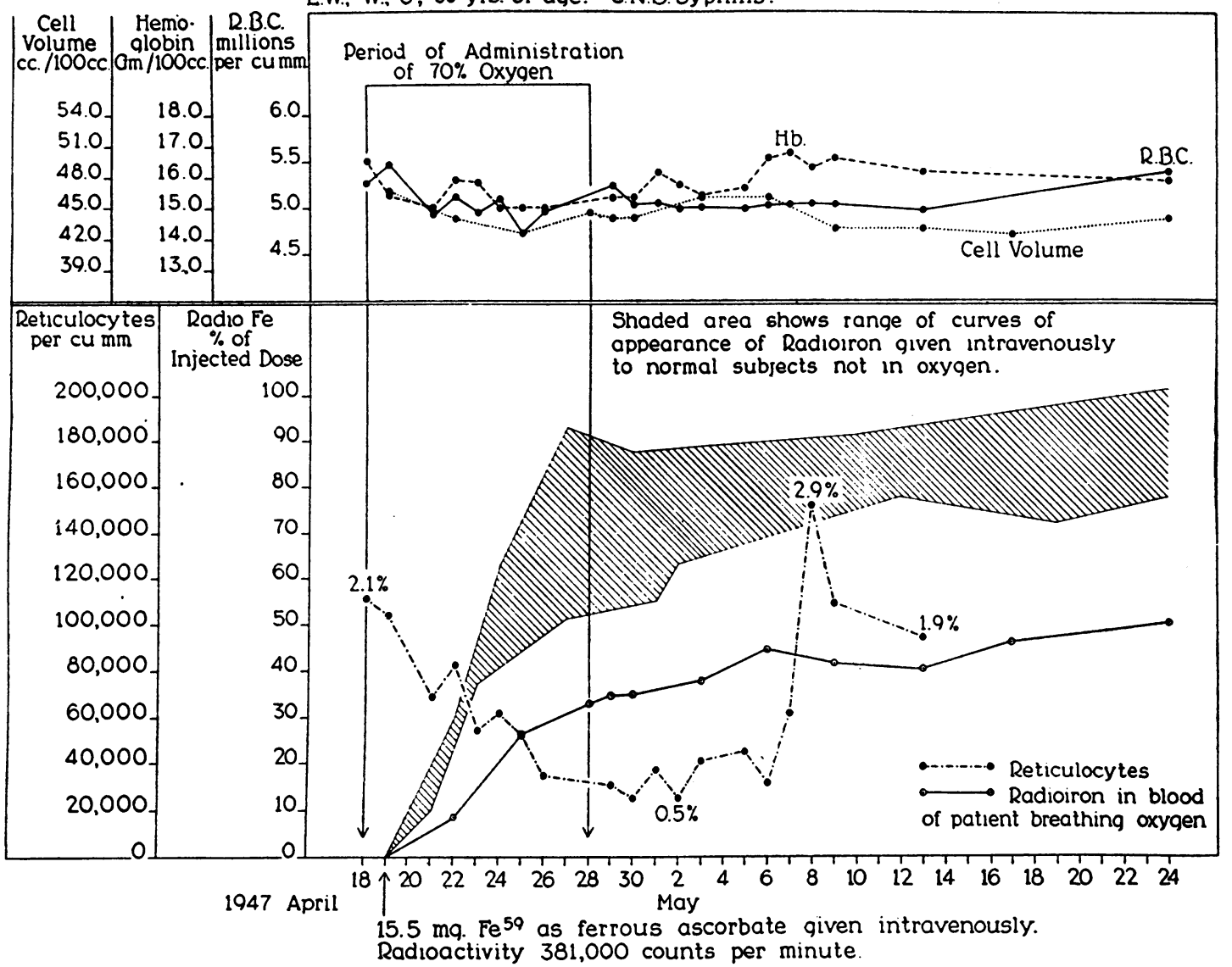

FIG. 8

any decrease produced by the oxygen inhalation would be difficult to measure with satisfactory accuracy. It was decided, therefore, to determine the rate at which intravenously injected radioiron was utilized for hemoglobin synthesis by subjects receiving high concentrations of oxygen, and to compare this result with a control observation on the same subject. Earlier work indicated that this technic may serve as a useful measure of the rate of hemoglobin formation (28). In a normal subject, the amount of newly synthesized, tagged hemoglobin which appears in the circulation should bear a direct relationship to the number of erthrocytes delivered from the bone marrow.

Two adult men of normal hematologic status were studied in this manner. The first of these, E. W. (Case 8, Figure 8), was given 70 per cent oxygen by face mask for 10 days. On repeated determinations during this time, the alveolar oxy- gen tension was found to vary from 341 to 433 $\mathrm{mm} . \mathrm{Hg}$; values for the arterial oxygen saturation lay between 100.6 and 101.7 per cent. The $\mathrm{pH}$ of arterial plasma was relatively constant (7.48 to 7.50) on four different occasions. The $\mathrm{CO}_{2}$ content gradually increased from 54.4 to 59.4 volumes per cent in arterial plasma, and from 45.5 to 50.6 volumes per cent in arterial whole blood; three days after oxygen was discontinued, the arterial plasma $\mathrm{CO}_{2}$ content was still 58.6 volumes per cent.

Twelve hours after the start of the oxygen period, $15.5 \mathrm{mg}$. $\mathrm{Fe}^{59}$ as ferrous ascorbate (total activity 381,000 counts per minute) were injected intravenously. In terms of the total amount of radioiron injected, 8.6 per cent was circulating on the third day, 26 per cent on the sixth day, and 33 per cent on the ninth day. For these calculations, the blood volume was assumed to be $80 \mathrm{cc}$. per kilo 
of body weight. It can be seen from Figure 8 that this increase was distinctly less than had been found in other normal subjects. More significant, however, is the comparison of this first curve of radioiron utilization with the second, in which the patient served as his own control (Figure 10, lower graph). Forty-seven days were allowed for stabilization of the $\mathrm{Fe}^{59}$ in blood before the second dose, containing $15.5 \mathrm{mg}$. $\mathrm{Fe}^{59}$ as ferrous ascorbate (activity $1,776,000$ counts per minute), was given. No known change had occurred in the hematologic status of the patient. No oxygen was administered. Two days later, 9.9 per cent of the injected radioiron had already appeared in circulating red cells; on the fifth day the amount had increased to 45.3 per cent. The subsequent rise was slower, but a level of 82 per cent was attained at the end of two weeks. This second curve fell within the limits of variation found for other nor- mal subjects (28), was distinctly higher than the first, and provides presumptive evidence that the inhalation of 70 per cent oxygen during the initial period had slowed the rate of erythrocyte delivery to the peripheral blood.

The reticulocytes were also followed carefully during the period of oxygen inhalation and for several weeks thereafter. The number of reticulocytes fell steadily from the initial value of 110,000 per cu. mm. (2.1 per cent ${ }^{7}$ ) to 34,700 (0.7 per cent) on the eighth day of oxygen administration, remained in the range of 25,000 to 31,300 ( 0.5 to 0.6 per cent) for four days after oxygen had been discontinued, and then rose again to reach a peak of 152,000 per cu. mm. (2.9 per cent) on the tenth day. Five more reticulocyte counts at wide in-

7 With the wet preparations used for reticulocyte counts in this laboratory, values of 2 to 4 per cent in normal subjects are not at all unusual.

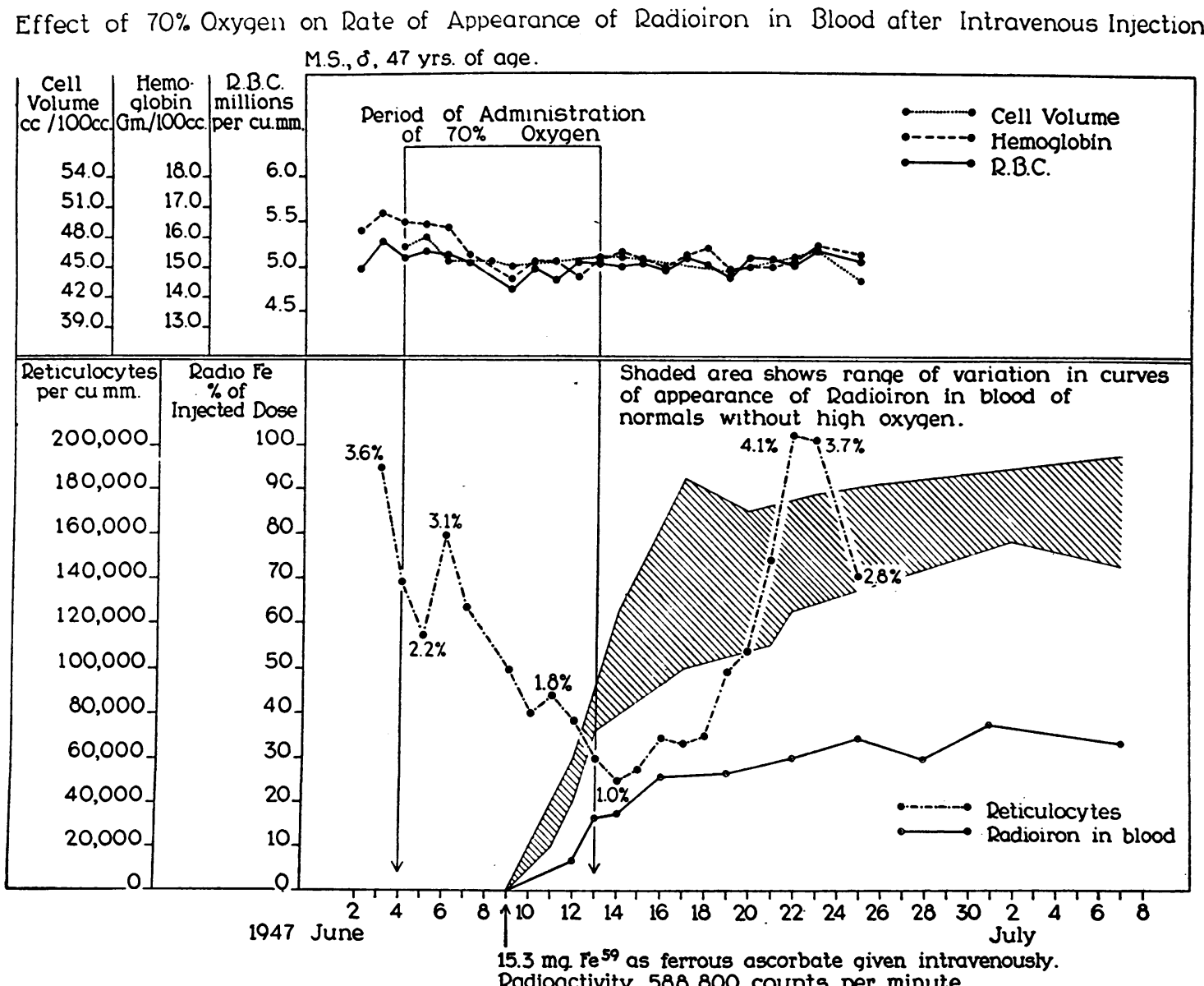

Fic. 9 
Utilization of $\mathrm{Fe}^{59}$ for $\mathrm{Hb}$ Synthesis by Two Normal Subjects During Control Periods and During Inhalation of $70 \%$ Oxygen
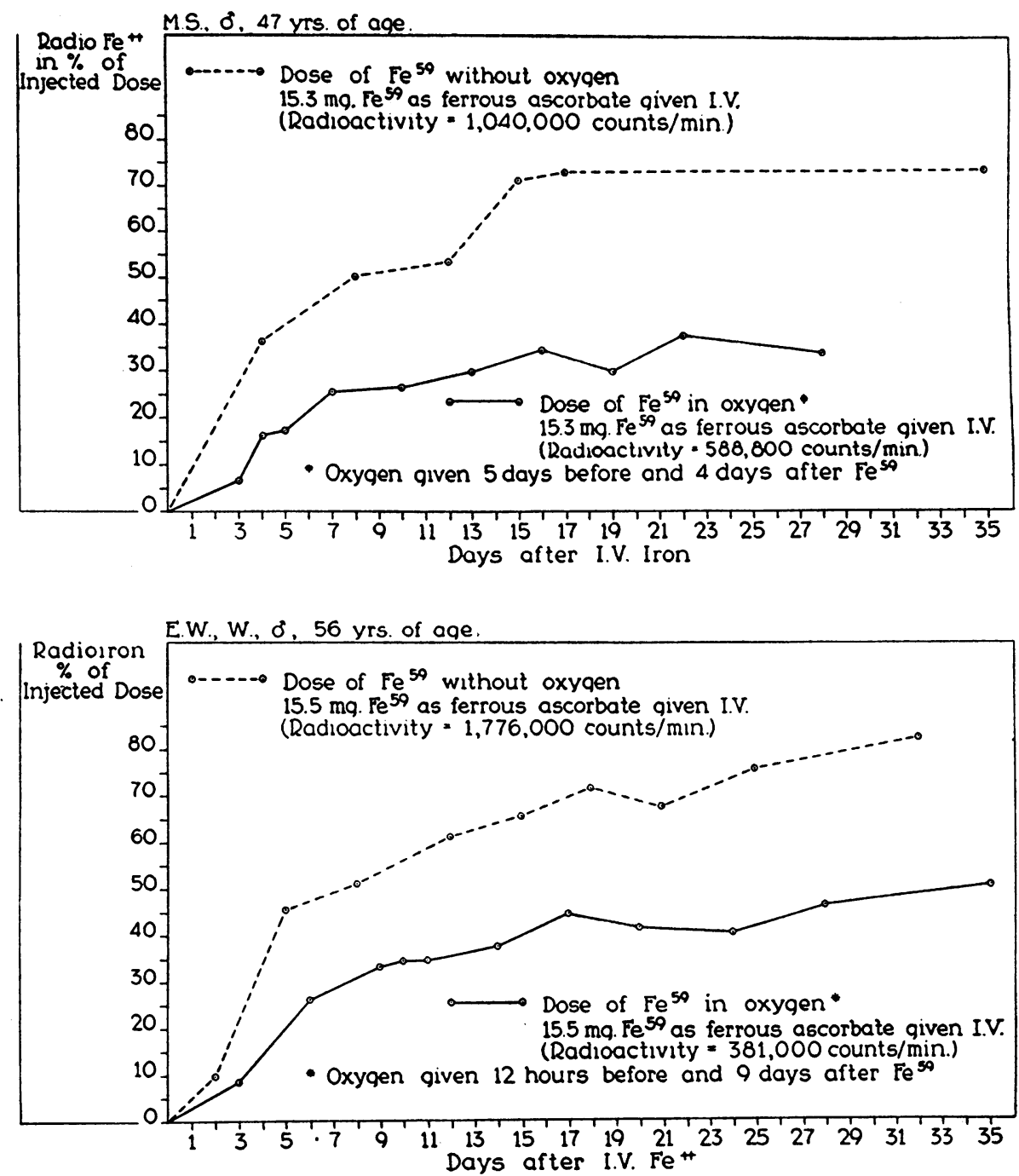

Fig. 10

tervals during the remainder of the period of observation fell between 70,000 to 118,000 per cu. $\mathrm{mm}$. ( 1.4 to 2.1 per cent). While the observed changes are small, the directional characteristics of the curves are very much like those found in the hemolytic anemias (Figures 1-3).

The second of the two hematologically normal subjects, M. S. (Case 9, Figure 9), was also given 70 per cent oxygen to breathe. The same type of study was made, but in this instance radioiron was injected on the fifth day of the oxygen period. Oxygen administration was continued for only an additional four days. Observations made as checks on the effectiveness of the inhalation therapy showed the following: 1) arterial oxygen saturation was found to be 100 and 99.7 per cent, as compared with a value of 93 per cent when room air was being inhaled; and 2) alveolar oxygen tension varied between 318 and $443 \mathrm{~mm}$. $\mathrm{Hg}$, as compared with pre-oxygen values of 93.5 and $91.1 \mathrm{~mm}$. $\mathrm{Hg}$. The $\mathrm{pH}$ of arterial plasma remained within the range of 7.41 to 7.44 . Carbon dioxide content of arterial blood was 56.7 volumes per cent early in the oxygen period and 55.1 volumes per cent on the ninth day.

In Figure 9 are recorded the radioiron utiliza- 
tion curves and the reticulocyte changes. The upper graph in Figure 10 compares the control rate of radioiron utilization by this patient with the rate obtained when the isotope was given during the oxygen administration. Results are entirely comparable to those obtained for the previous patient (E. W., Figure 8).

The decreased utilization of radioiron by these two "normal" subjects, the fall in reticulocytes during the oxygen periods, and their return to control values after oxygen administration was stopped are interpreted as indirect evidence for the depression of erythrocytogenesis by high concentrations of inspired oxygen.

\section{v. DISCUSSION}

The data presented in this report indicate that oxygen breathed in concentrations of 50 per cent or more depresses the rate of erythropoiesis in normal human subjects, in patients with chronic hemolytic anemias, and in patients with pernicious anemia. This effect of oxygen occurred without any alteration in the $\mathrm{pH}$ of the arterial plasma (Cases 8 and 9), in the absence of toxic manifestations (Cases 2, 5-9), and with concentrations of oxygen as low as 50 per cent (Case 2). The hyperoxygenation of the alveolar air and the arterial blood was demonstrated by routine determinations. Increases of 4 to 6 volumes per cent in the carbon dioxide content of the arterial blood were found in some of the patients during the oxygen periods; the rises were neither progressive nor constant, and the variable increases in carbon dioxide tension, when they occurred, were probably not significant in degree.

That the breathing of 50 to 100 per cent oxygen at a total gas pressure of one atmosphere will significantly increase the availability of oxygen in the arterial blood is apparent when the degree of increase in oxygen tension is recognized. For instance, when 50 per cent oxygen is breathed, the tension of oxygen in the alveolar air is increased from approximately 100 to $300 \mathrm{~mm}$. Hg. Since the oxygen tension in the arterial blood approximates that in the alveoli (42), the arterial oxygen tension is probably also increased from 100 to 300 $\mathrm{mm}$. Hg. It is reasonable to assume that the high tension renders the oxygen so much more easily available to the tissues that the added amount has an effect out of proportion to its small volume.

The mechanism through which oxygen tension of the environment exerts its effect on erythropoiesis is not known with certainty. The most commonly held theory, for which there is considerable support, implies that one of the factors which controls red blood cell production is the oxygen tension in the marrow itself. Since chronic hypoxia is associated with secondary polycythemia $(2,43,44)$, it is assumed that the resultant low oxygen tension in marrow stimulates erythrocytogenesis. Conversely, if erythroid tissue is exposed to an increased oxygen tension, the rate of red cell formation would be expected to decrease. The results of the present investigation are compatible with this idea. No attempt was made, however, to measure directly the changes in oxygen tension of the bone marrow during periods of oxygen administration; it was assumed that some of the increased tension in arterial blood would be transmitted to the marrow. This assumption was based mainly on the work of Campbell (2) which demonstrated that significant increases did occur in the oxygen tension of tissues in rabbits exposed to high concentrations of oxygen.

Several important considerations are difficult to reconcile with the above theory. It is strange, for instance, that actively dividing and maturing nucleated red blood cells which consume oxygen (45) should multiply more rapidly when the oxygen tension is low. Under conditions of tissue culture, furthermore, red cell progenitors grow less well when oxygen concentration is reduced from 20 to 15 per cent or less, and actually seem to be stimulated by an atmosphere containing 50 per cent oxygen (46). If the theory is correct, one would expect that the oxygen saturation of blood in the bone marrow would be low during periods of increased red cell production. Grant and Root (47), however, found that when erythropoiesis was stimulated in dogs by a single hemorrhage of one-third the blood volume, the oxygen saturation and tension of bone marrow blood fell for only three to five hours, returned promptly to control levels, and remained there during the phase of red cell regeneration. These investigators were further able to produce the same degree of anemia and red cell regeneration 
in dogs by intermittent small hemorrhages over a three-day period without the occurrence of any significant fall in the oxygen saturation of bone marrow blood. Moreover, in patients with chronic anemias of varied etiology, Berk and his associates (48) obtained values for the oxygen saturation of bone marrow blood which were no lower than in normal subjects. It may be argued that the technics used in these last two studies provided no true measure of oxygen tension in the marrow because the samples collected contained varying amounts of venous and arterial blood, and that the behavior of cells in tissue culture is not an adequate index of their physiologic activity in their natural environment, but alternative explanations for the way in which the effect of oxygen is mediated should be explored.

During the course of the investigations described in this paper, it became clear that the depressant effects of high concentrations of inspired oxygen on erythropoiesis were more dramatic and much easier to demonstrate in the subjects with sickle cell anemia than in any of the other patients. The reasons for this difference are obscure, but an interesting suggestion was made to the authors by Ham and Castle (49). At relatively low oxygen tensions, the viscosity of blood from patients with sickle cell anemia is quite high. Relatively slight increases in oxygen tension in the marrow capillaries of patients with sickle cell anemia may be lower than in other anemias of comparable severity because the capillary blood may have a high viscosity, and circulation may be slowed. If this is true, then high concentrations of inspired oxygen might decrease the viscosity and accelerate the rate of capillary circulation. Consequently, the marrow would be subjected to a greater total quantity of blood as well as to an increased arterial oxygen tension. As a result, the net increase in oxygen tension which would occur in the marrow of patients with sickle cell anemia might well be greater than in other subjects. If high oxygen tensions are indeed transmitted to the marrow and exert their depressant effects on erythroid cells themselves, then this explanation is a rational one. The authors have none other to offer.

Finally, a brief statement should be made about the absence or the relative mildness of the manifestations of oxygen toxicity experienced by the subjects in this study. Comroe and his associates demonstrated that 82 per cent of normal men experienced substernal distress after breathing 100 per cent oxygen for 24 hours; nearly half of their subjects were able to tolerate 75 per cent oxygen for a similar period of time; 50 per cent oxygen produced no symptoms (30). Even though nurses were kept at the bedside of our patients to keep the masks adjusted, there were unquestionably many interruptions of the oxygen administration. Control determinations of arterial and alveolar oxygen were made, but these reflect primarily the conditions existing only at the time of the sampling. No conclusions are drawn about oxygen toxicity from these studies. The important thing is that the amount of oxygen administered did produce the evidences of erythroid depression which have been described.

\section{SUMMARY AND CONCLUSIONS}

Oxygen was administered continuously for eight to 14 days through a meter face mask to two patients with sickle cell anemia, one with congenital hemolytic anemia, four with untreated pernicious anemia, and to two men with late syphilis in whom the red cell equilibrium was normal. With oxygen concentrations of 50 per cent or more in the inspired air, the following evidences of erythroid depression were regularly observed:

1. Chronic hemolytic anemia:

During the oxygen period, there was a dramatic decrease in the number of reticulocytes, a fall in the red blood cell count of approximately one million cells, and a slower rate of radioactive iron utilization for hemoglobin synthesis. After oxygen was discontinued, a marked reticulocytosis developed, the red cells returned rapidly to the control level, and the utilization of radioactive iron was accelerated.

2. Pernicious anemia :

Injection of therapeutic doses of liver extract or of Vitamin $B_{12}$ while high concentrations of oxygen were being given caused a submaximal reticulocyte response. During the post-oxygen period a second reticulocyte crisis, larger than the first, occurred in each instance. 
3. Subjects with normal blood formation: Radioactive iron, injected intravenously during oxygen administration, was delivered to the peripheral blood as newly formed hemoglobin at a rate distinctly less than the normal. There was also a small but definite decrease in reticulocytes. After the oxygen mask was removed, the reticulocyte level rose to control values. While these reticulocyte changes were of small magnitude, they were similar in direction and timing to the more dramatic changes observed in chronic hemolytic anemias. Several weeks after these observations were completed, the utilization of radioactive iron was again studied so that each subject could serve as his own control. Curves obtained after these second injections fell within the range previously established for normal subjects. There remained no doubt, therefore, that the utilization of iron was depressed during the oxygen period.

The above changes were observed even in those subjects in whom no detectable manifestations of oxygen toxicity appeared. The plasma $\mathrm{pH}$ and the carbon dioxide content of blood were not significantly altered during oxygen administration.

The results of this study indicate that high tensions of inspired oxygen depress erythrocytogenesis in the human subject, and provide further evidence that oxygen tension of the arterial blood is one of the principal regulators of erythropoietic activity. The mechanism through which this regulatory effect may be mediated was reviewed.

\section{CASE SUMMARIES}

Case 1 (Figure 1). L. M. B., a Negro female aged 29 years, had been admitted to the Barnes Hospital eight times since 1939 because of sickle cell anemia. Frequent examinations through the years have regularly revealed a moderate to marked anemia, reticulocytosis, marked degrees of sickling in formalin-fixed venous blood, increased urobilinogen output and other findings characteristic of sickle cell anemia.

On this admission, in January 1947, she complained of severe aching pain in the right thigh and was apparently in a mild crisis. Positive physical findings included asthenic habitus, pallor, a moderately enlarged heart with a blowing precordial systolic murmur loudest at the apex and a mid-diastolic low-pitched third sound, barely palpable spleen, and complete absence of redness, heat or swelling in the painful region of the right thigh.

Examination of the blood revealed the red cell count to be $2,940,000$ per cu. mm., hemoglobin $9.0 \mathrm{Gm}$. per cent, reticulocytes 409,000 per cu. mm. (13.9 per cent), and white blood cells 11,550 per cu. $\mathrm{mm}$. The differential count of 100 leucocytes showed 1 eosinophile, 1 myelocyte, 6 band forms, 63 segmented neutrophiles, 19 lymphocytes, and 10 monocytes. Marked sickling of the red cells was present in the supravital preparation. Results of further laboratory studies including those of the urine, feces and blood non-protein nitrogen were not remarkable, except for the evidences of increased urobilinogen excretion.

The patient's symptoms subsided within three days. An increase of reticulocytes to 932,000 per cu. mm. (24.4 per cent) followed the critical episode, but by the ninth hospital day her usual hematologic equilibrium appeared to have been reestablished.

While the patient was breathing 80 per cent oxygen, her nose and throat felt dry. She complained intermittently of mild headaches, and sharp pains at the costal margins or occasionally beneath the scapulae. During the last five days slight $(0.5-4.0 \mathrm{cc}$.) epistaxis occurred once or twice a day. At no time were there physical signs of pulmonary parenchymal or pleural pathology. Twelve hours after the oxygen was stopped, severe headache, anorexia, nausea and one episode of vomiting appeared. During the next 36 hours there was rapid improvement, but headache, anorexia, afternoon fever reaching $38.4^{\circ} \mathrm{C}$., and a feeling of exhaustion persisted for three days.

Case 2 (Figure 2). G. P., a Negro housewife aged 27 years, is a well documented case of sickle cell anemia with seven previous admissions to the Barnes Hospital for hemolytic crises, leg ulcers and the deliveries of her two children. This time she was admitted June 6, 1948, for treatment of a chronic ulcer on her right ankle.

Physical examination revealed an asthenic habitus, pallor of nail beds and mucous membranes, muddy sclerae, tortuous veins in the ocular fundi, slightly enlarged heart with a Grade II apical and basal systolic murmur and an inconstant third heart sound, palpable liver thought to be normal in size, very old scars of previous appendectomy and of splenectomy, and an ulcer $3 \times 6 \mathrm{~cm}$. in diameter, $1-2 \mathrm{~cm}$. deep at the right medial malleolus, associated with deep induration causing an equino-varus malposition of the ankle joint.

Examination of the blood revealed the red cell count to be $2,600,000$ per cu. mm., hemoglobin $8.6 \mathrm{Gm}$. per cent, reticulocytes 471,000 per cu. $\mathrm{mm}$. (18.1 per cent), and white cell count of 13,100 per cu. mm. of which 1 per cent were eosinophiles, 5 band forms, 70 segmented neutrophiles, 15 lymphocytes and 9 monocytes. There was marked sickling of the erythrocytes in the supravital preparation. The total serum bilirubin was $3.41 \mathrm{mg}$. per cent of which $0.25 \mathrm{mg}$. per cent gave an immediate reaction. The cephalin cholesterol flocculation test was negative. Thymol turbidity was 7.0 units.

No signs or symptoms of oxygen toxicity appeared 
in this patient at any time during the whole period of observation.

Case 3 (Figure 3). L. D., a white male 17 years of age, was admitted to the Barnes Hospital in September, 1946, complaining of anemia, jaundice and a big spleen "all my life." There had been exacerbations of the anemia and jaundice accompanied by weakness, dizziness, aching in the extremities and dark urine as often as twice a year; many episodes had been severe and prostrating. A younger sister was similarly affected, two brothers had died in infancy, and two of his father's brothers, a paternal cousin, and granduncle had died at early ages with anemia.

Positive physical findings included pallor, faint icterus, minimal enlargement of regional lymph nodes, a normal or slightly enlarged heart with a short, soft apical systolic murmur, and a firm non-tender spleen extending 2 to $3 \mathrm{~cm}$. below the level of the umbilicus.

Examination of the blood on admission showed a red cell count of 2,790,000 per cu. mm., hemoglobin $7.4 \mathrm{Gm}$. per cent, reticulocytes 690,000 per cu. mm. (24.8 per cent) and white cells 7,350 per cu. mm. with a normal differential count. Further laboratory studies revealed "spherocytosis" with markedly increased osmotic fragility of the red cells (hemolysis began in 0.71 per cent sodium chloride and was complete in 0.43 per cent). Total urobilinogen excretion averaged 1,830 mg. daily. A sample of sternal marrow showed marked normoblastic hyperplasia. The lungs and gall bladder were normal on $x$-ray examination.

Soon after oxygen was begun, this boy noted tingling of his fingertips and vague substernal discomfort. On the third day, he complained of persistent sharp pains in the upper chest anteriorly and posteriorly, irritation in his throat, and pain in the left ear (a mild aerotitis relieved by Ephedrine nose drops). These complaints, except for the earache, persisted throughout the oxygen period. On the fifth day, a low-grade fever appeared and rose steadily to reach about $39^{\circ} \mathrm{C}$. on the eighth day. The patient developed a cough, and the administration of oxygen was stopped although examination did not reveal any abnormality in the lungs. Within an hour the size of his heart was found to be increased. The pulmonic second sound was quite loud; short blowing systolic and diastolic murmurs were audible at the cardiac apex and at the left border of the sternum; a short blowing systolic murmur was also heard over the aortic area. An electrocardiogram showed a sinus tachycardia (140 per minute) without other deviations from the normal. Within 48 hours, on bed rest, all the foregoing symptoms and signs had disappeared except for the mildly productive cough which persisted three or four more days.

Two weeks after the administration of oxygen was terminated, a splenectomy was performed.

Case 4 (Figure 4). E. B., a former lead miner, 55 years of age, was admitted to the Medical Service of the Barnes Hospital on January 7, 1947. His history revealed a gradual onset of stiffness in his legs and numbness of his feet. His tongue had been sore intermittently. In recent months he had been troubled by poor appetite, easy fatigue, and dyspnea on exertion. About seven years previously he had an ill-defined swelling of his abdomen for about one year.

Physical examination showed atrophy of papillae at the periphery of the tongue, pallor of the skin and mucous membranes, a soft blowing apical systolic murmur, no cardiac enlargement, a network of fine venules in the region of the attachment of the diaphragm, normal sized liver, slight paresthesias and diminution in perception of vibration in the left upper extremity below the elbow, more marked loss of perception of vibration below the knees and a slightly wide-based gait.

Examination of the blood revealed the red cell count to be $3,100,000$ per cu. mm., hemoglobin $10.9 \mathrm{Gm}$. per cent, reticulocytes 96,000 per cu. mm. (3.1 per cent), platelets 750,000 per cu. mm., and white cells 8,050 per cu. mm. with a differential count of 100 cells showing 1 band form, 74 segmented neutrophiles, 2 eosinophiles, 20 lymphocytes, 3 monocytes. The mean corpuscular volume was $122 \mathrm{cu}$. microns, the mean corpuscular hemoglobin 43 $\mu \mu \mathrm{g}$., and the mean corpuscular hemoglobin concentration 35 per cent. An aspirated sample of sternal marrow showed the megaloblastic hyperplasia characteristic of pernicious anemia in relapse. The icterus index was 14 units. Histamine-fast achlorhydria was demonstrated. Other laboratory procedures which yielded normal results included routine analysis of urine and feces, blood non-protein nitrogen, total serum protein, albumin and globulin, cephalin cholesterol flocculation, thymol turbidity, bromsulphalein and Kahn tests, chest roentgenogram and electrocardiogram.

During the oxygen period the patient complained intermittently of "lightheadedness," restlessness at night, and slight headache. After six days in oxygen, he noted hoarseness and a rather dry cough, and on the seventh day, he had experienced sharp substernal and interscapular pain which was not present the next two days. The concentration of oxygen was gradually reduced to that of the normal atmosphere over a period of eight hours, and for two days the patient noted fatigue and slight weakness. No abnormal physical signs could be detected on examination of his lungs.

Case 5 (Figure 5). M. S., a white widow aged 70 years, was admitted to the Barnes Hospital in November, 1948 with the history of numbness and tingling of her hands and feet, poor appetite, weight loss and easy fatigability beginning five years previously. Her symptoms progressed more rapidly during the last year and included increased acroparesthesias with impairment of ability to carry out fine movements with the fingers, a tendency to sway and stumble while walking, weakness, dyspnea on exertion, repeated episodes of sore tongue, and indigestion with occasional vomiting. There had been a weight-loss of 30 pounds in five years.

Pertinent positive data on physical examination included white hair, pallor of skin and mucous membranes, red slick tongue, minimal enlargement of the heart with a Grade II, high-pitched, blowing systolic murmur heard over the precordium but loudest at the cardiac apex, greatly diminished perception of vibration in the legs and of position in the toes, absent knee and ankle jerks, 
swaying in Romberg's position and impairment of ability to recognize small objects in the hands or to perform fine movements with the fingers.

The blood revealed a red cell count of 2,350,000 per cu. mm., hemoglobin $11.3 \mathrm{Gm}$. per cent, reticulocytes 80,000 per cu. mm. (3.4 per cent), platelets 332,000 , and white cells 4,800 per cu. $\mathrm{mm}$. The differential count of 100 white cells revealed eosinophiles 4, segmented neutrophiles 52 , lymphocytes 41 , and monocytes, 3 ; the red cells showed marked macrocytosis, anisocytosis and poikilocytosis. The sample of sternal marrow was grossly hyperplastic and megaloblasts were numerous. Histamine refractory achlorhydria was demonstrated. X-ray studies of the chest, spine, and upper gastro-intestinal tract were non-contributory.

Although the concentration of oxygen given to this patient was increased from 80 to 95 per cent during the oxygen period, she developed no symptoms of oxygen toxicity.

Case 6 (Figure 6). J. B., a white man, 70 years of age, was admitted to the Barnes Hospital complaining of numbness, tingling and clumsiness of his hands of two years' duration. These symptoms had progressed more rapidly in recent months. His tongue had been sore for a few days seven months previously. He had eaten about one-half pound of cooked liver six to eight days before his admission to the Hospital.

Physical examination revealed atrophy of papillae on the edge of the tongue, questionable hepatomegaly, hard nodule in the left lobe of the prostate, definite clumsiness of the hands in finer movements such as tying knots in a cord, and diminished but not absent perception of vibration distal to the elbows and knees.

Examination of the blood revealed a red cell count of $3,300,000$ per cu. mm., hemoglobin $13.5 \mathrm{Gm}$. per cent, reticulocytes 109,000 per $\mathrm{cu}$. mm. (3.3 per cent), platelets 330,000 per $\mathrm{cu}$. $\mathrm{mm}$. and white cells 6,200 , with the differential count of 100 cells showing 1 basophile, 2 eosinophiles, 1 band form, 64 segmented forms, 16 lymphocytes and 16 monocytes. The red cells appeared macrocytic and varied remarkably in size and shape. The corpuscular constants were: mean volume $126 \mathrm{cu}$. microns, mean hemoglobin $45 \mu \mu$ g., and mean hemoglobin concentration 35 per cent. The aspirated sternal marrow sample was very cellular and showed a definite shift to younger erythroid forms with a moderate number of megaloblasts as well as a few macrometamyelocytes. Histamine-fast achlorhydria was demonstrated.

Further laboratory examinations revealed repeatedly normal cephalin cholesterol flocculation, bromsulfalein clearance and prothrombin, thymol turbidity of 6.2 and 8.7 units, total serum protein of $6.9 \mathrm{Gm}$. per cent (albumin 3.8 and globulin $3.1 \mathrm{Gm}$. per cent), serum acid phosphatase 2.3 Bodansky units, normal spinal fluid with normal dynamics, and "indeterminate" findings on roentgenograms of the chest, spine, pelvis, and gastro-intestinal tract. Diagnoses of pernicious anemia, generalized arteriosclerosis, and benign hypertrophy of the prostate were made.
During the first four days after the patient was admitted to the hospital, his red blood cell level fell steadily to $2,600,000$ per cu. $\mathrm{mm}$., the packed cell volume to 35 per cent, the hemoglobin to $12.5 \mathrm{Gm}$. per cent, and the reticulocytes to $81,000 \mathrm{cu}$. $\mathrm{mm}$. (3.1 per cent). The white cells and platelets did not change significantly. The free erythrocyte protoporphyrin was $21.5 \mu \mathrm{g}$. per 100 cc. of packed red cells on the first day, 28.9 on the second, 27.7 on the third, and $21.2 \mu \mathrm{g}$. on the fifth day. After this small hematologic response (apparently produced by the liver he had eaten about one week before admission) had passed, the administration of 70 per cent oxygen was begun and maintained for 12 days.

Both subjective and objective evidence of clinical improvement in the patient was noted after the therapy with liver extract. His appetite improved and he became less clumsy in handling his eating utensils, tying knots in a cord, and fastening buttons on his clothes.

This patient showed no symptoms or signs of toxic effects of the oxygen.

Case 7 (Figure 7). W. L., a white male 66 years of age, was admitted to the Genito-urinary Service of the Barnes Hospital because of symptoms of obstruction to the flow of urine due to hypertrophy of the prostate. The discovery of anemia associated with combined system disease led to his transfer to the Medical Service for further study.

This man had been troubled by numbness and tingling in his hands and feet for at least two years, and in recent months experienced increasing difficulty in manipulating small objects. He had noted anorexia, dyspnea on moderate exertion, and weight loss of ten pounds.

Pertinent positive data on physical examination included a slight degree of pallor of the skin and mucous membranes, smoothness without redness of the tongue, moderate diffuse enlargement of the prostate, marked diminution of perception of position and vibration in both hands and feet, extreme difficulty in manipulating small objects and in writing his name, a moderately widebased gait, equivocal plantar responses, and advanced sclerosis of the palpable arteries.

Examination of the blood revealed a red cell count of 2,250,000 per cu. mm., hematocrit 30 per cent, hemoglobin $10.5 \mathrm{Gm}$. per cent, reticulocytes 29,000 per cu. mm. (1.3 per cent) and white cells 8,650 with the differential count of 100 cells showing 1 eosinophile, 1 myelocyte, 1 band form, 68 segmented forms, 23 lymphocytes and 6 monocytes. The aspirated sample of sternal marrow revealed a moderate degree of megaloblastic arrest. Histamine-fast achlorhydria was demonstrated. The centrifuged urine sediment contained small clumps of pus cells. The blood non-protein nitrogen was $24 \mathrm{mg}$. per cent and the total serum protein $6.9 \mathrm{Gm}$. per cent (albumin 4.3 and globulin 2.6). Roentgenologic examination of the gastro-intestinal tract revealed a large diverticulum of the lower third of the esophagus.

No manifestations of oxygen toxicity were detected while the patient breathed 70 per cent oxygen. The usual subjective improvement followed injection of liver extract. 
Case 8 (Figure 8). E. W., a white male 56 years of age, was admitted to the Barnes Hospital for diagnosis and treatment of a neurologic disorder. Five years before admission, his physician discovered a positive serologic test for syphilis; a full course of bismuth and arsenic therapy was apparently given. There were no further symptoms until 15 months before admission when he suffered severe shooting pain at night across the top of his right shoulder; the pain was aggravated by movement or by coughing and lasted about a month. Shortly thereafter, stinging pain and numbness appeared over the left buttock and thigh, and concomitantly he began to drag his right leg when he walked. He received 45 injections of mapharsen and about 1.1 million units of penicillin with incomplete relief. Twitching of muscle groups in both hands and legs was noted from time to time.

Remarkable data on physical examination included a blood pressure of $160 / 85 \mathrm{~mm}$. $\mathrm{Hg}$, irregular pupils which reacted to light, restricted visual fields, severe bilateral old chorioretinitis, hyperesthesia and paresthesia to pin prick and to cold over the lateral surface of left leg and hip, a zone of hyperesthesia low in the left flank, weakness of the right triceps brachii $M$. and the right quadraceps femoris M., and fascicular twitching in both forearms. The left triceps, left Achilles, and the right patellar reflexes were increased; the Babinski response was positive on the right and equivocal on the left.

Routine tests of the urine and feces were not remarkable. The blood Kahn was negative but the KolmerWassermann was positive. The electrocardiogram was normal. Spinal fluid studies revealed an initial pressure of $210 \mathrm{~mm}$. water, final pressure 160, lymphocytes 6 per cu. mm., protein $129 \mathrm{mg}$. per cent, and Wassermann test positive. Manometrics revealed no block and myelograms were non-contributory. Roentgenograms of the spine revealed generalized osteoarthropathy with slight posterior subluxation of the third cervical vertebra on the fourth, and narrowing and destruction of intervertebral discs between the fifth and sixth, and sixth and seventh cervical vertebrae. The ophthalmologic consultant made a diagnosis of primary pigment degeneration of the retina. Visual fields were markedly constricted. The patient was thought to have an atypical form of neurosyphilis.

Examination of the blood revealed the red cell count to be $5,260,000$ per cu. mm., hemoglobin $16.5 \mathrm{Gm}$. per cent, reticulocytes 110,000 per $\mathrm{cu} . \mathrm{mm}$. (2.1 per cent), platelets 500,000 and white cells 9,450 with the differential count of 100 cells showing 2 eosinophiles, 1 band form, 82 segmented neutrophiles, 12 lymphocytes, and 3 monocytes.

The administration of 70 per cent oxygen was begun, and 12 hours later $15.5 \mathrm{mg}$. Fe (activity 381,000 counts per minute) were injected intravenously. Changes in the red cell elements and appearance of the radioiron in blood have been described in the main body of the paper. White cell levels varied from 4,950 to 10,500 per cu. mm., the lowest counts being obtained toward the end of the oxygen period and highest five days after oxygen ad- ministration was stopped. The platelet counts $(300,000$ to 650,000 per $\mathrm{cu} . \mathrm{mm}$.) showed changes similar in direction and timing.

No toxic effects from the 70 per cent oxygen were noted. Treatment of the neurosyphilis with penicillin was begun on the fourth day of the oxygen period; 50,000 units were injected every three hours for 17 days.

Case 9 (Figure 9). M. S., a Filipino bar-tender 47 years of age, was admitted to the Barnes Hospital for treatment of asymptomatic neurosyphilis. $\mathrm{He}$ had no neurologic complaints.

Positive data obtained on physical examination revealed only a perforated left eardrum with a small amount of purulent drainage. Neurologic examination showed no remarkable pathologic changes.

Pertinent laboratory data included normal blood counts and corpuscular constants, positive blood Wassermann test, normal serum proteins and cephalin cholesterol flocculation, thymol turbidity 6 units, and normal blood nonprotein nitrogen. Urine analysis was negative and the feces did not contain occult blood. A spinal puncture yielded clear fluid under normal pressure with protein $57 \mathrm{mg}$. per cent, mononuclear cells 54 per cu. mm., Wassermann positive, and gold curve 1111100000 . An x-ray film of the chest showed no abnormalities.

The patient received 50,000 units of penicillin every three hours for 17 days beginning seven days before administration of 70 per cent oxygen was started. No toxic manifestations of the oxygen were observed.

\section{BIBLIOGRAPHY}

1. Bornstein, A., Ueber den Einfluss der komprimierten Luft auf die Blutbildung. Archiv. f. d. ges. Physiol., 1911, 138, 609.

2. Campbell, J. A., Prolonged alterations of oxygen pressure in the inspired air with special reference to tissue oxygen tension, tissue carbon dioxide tension, and hemoglobin. J. Physiol., 1927, 62, 211.

3. Campbell, J. A., Further observations on oxygen acclimatisation. J. Physiol., 1927, 63, 325.

4. Barach, A. L., and Richards, D. W., Jr., Oxygen therapy in pulmonary tuberculosis. Am. Rev. Tuberc., 1932, 26, 241.

5. Barcroft, J., Hunt, G. H., and Dufton, D., The treatment of chronic cases of gas poisoning by continuous oxygen administration in chambers. Quart. J. Med., 1920, 13, 179.

6. Reinhard, E. H., Moore, C. V., Dubach, R., and Wade, L. J., Depressant effects of high concentrations of inspired oxygen on erythrocytogenesis. Observations on patients with sickle cell anemia with a description of the observed toxic manifestations of oxygen. J. Clin. Invest., 1944, 23, 682.

7. Callender, S. T. E., Nickel, J. F., and Moore, C. V., Sickle cell disease: studied by measuring the survival of transfused red blood cells. J. Lab. \& Clin. Med., 1949, 34, 90.

8. Singer, K., Robin, S., King, J. C., and Jefferson, R. N., The life span of the sickle cell and the 
pathogenesis of sickle cell anemia. J. Lab. \& Clin. Med., 1948, 33, 975.

9. Evelyn, K. A., A stabilized photoelectric colorimeter with light filters. J. Biol. Chem., 1936, 115, 63.

10. Wintrobe, M. M., The size and hemoglobin content of the erythrocyte. Methods of determination and clinical application. J. Lab. \& Clin. Med., 1932, 17, 899.

11. Wintrobe, M. M., Macroscopic examination of the blood, discussion of the value and description of the use of a single instrument for determination of sedimentation rate, volume of packed red cells, leukocytes and platelets, and of icterus index. Am. J. Med. Sc., 1933, 185, 58.

12. Dameshek, W., A method for the simultaneous enumeraton of blood platelets and reticulocytes. Arch. Int. Med., 1932, 50, 579.

13. Malloy, H. T., and Evelyn, K. A., The determination of bilirubin with the photoelectric colorimeter. J. Biol. Chem., 1937, 119, 481.

14. Ducci, H., and Watson, C. J., The quantitative determination of the serum bilirubin with special reference to the prompt-reading and the chloroformsoluble types. J. Lab. \& Clin. Med., 1945, 30, 293.

15. Watson, C. J., Studies of urobilinogen. I. An improved method for the quantitative estimation of urobilinogen in urine and feces. Am. J. Clin. Path., 1936, 6, 458.

16. Kelly, W. D., Lewis, J. H., and Davidson, C. S., The determination of urine urobilinogen: The interpretation of the rate of color development of the Ehrlich reaction. J. Lab. \& Clin. Med., 1946, 31, 1045.

17. Moore, C. V., Minnich, V., and Welch, J., Studies in iron transportation and metabolism. III. The normal fluctuations of serum and "easily splitoff" blood iron in individual subjects. J. Clin. Invest., 1939, 18, 543.

18. Barkan, G., and Walker, B. S., Determination of serum iron and pseudohemoglobin iron with $O$ phenanthroline. J. Biol. Chem., 1940, 135, 37.

19. Grinstein, M., Silva, J. A., and Wintrobe, M. M., The anemia of infection. VII. The significance of free erythrocyte protoporphyrin, together with some observations on the meaning of the "easily split-off" iron. J. Clin. Invest., 1948, 27, 245.

20. Moore, C. V., Dubach, R., Minnich, V., and Roberts, $H$. K., Absorption of ferrous and ferric radioactive iron by human subjects and by dogs. J. Clin. Invest., 1944, 23, 755.

21. Cullen, G. E., Studies of acidosis. XIX. The colorimetric determination of hydrogen-ion concentration of blood plasma. J. Biol. Chem., 1922, 52, 501.

22. Evelyn, K. A., and Malloy, H. T., Unpublished (included in the "Notes on operation of the Evelyn photoelectric colorimeter" published by the Rubicon Company, Philadelphia, Penna., 1939).
23. Grinstein, M., and Wintrobe, M. M., Spectrophotometric micromethod for the quantitative determination of the free erythrocyte protoporphyrin. J. Biol. Chem., 1948, 172, 459.

24. Henderson, Y., and Morriss, W. H., Applications of gas analysis. I. The determination of carbon dioxide in alveolar air and blood and the carbon dioxide combining powers of plasma and whole blood. J. Biol. Chem., 1917, 31, 217.

25. Van Slyke, D. D., and Sendroy, J., Jr., Manometric analysis of gas mixtures. I. The determination, by simple absorption, of carbon dioxide, oxygen and nitrogen in mixtures of these gases. J. Biol. Chem., 1932, 95, 509.

26. (a) Van Slyke, D. D., and Neill, J. M., The determination of gases in blood and other solutions by vacuum extraction and manometric measurement. J. Biol. Chem., 1924, 61, 523.

(b) Peters, J. P., and Van Slyke, D. D., Quantitative Clinical Chemistry. Vol. II. Methods. Williams and Wilkins, Baltimore, 1932, pp. 324-328.

27. Barach, A. L., and Eckman, M., A mask apparatus which provides high oxygen concentrations with accurate control of the percentage of oxygen in the inspired air and without accumulation of carbon dioxide. J. Aviation Med., 1941, 12, 39.

28. Dubach, R., Moore, C. V., and Minnich, V., Studies in iron transportation and metabolism. V. Utilization of intravenously injected radioactive iron for hemoglobin synthesis, and an evaluation of the radioactive iron method for studying iron absorption. J. Lab. \& Clin. Med., 1946, 31, 1201.

29. Watson, C. J., Grinstein, M., and Hawkinson, V., Studies of protoporphyrin. IV. A comparison of the erythrocyte protoporphyrin concentration with the reticulocyte percentage under experimental and clinical conditions. J. Clin. Invest., 1944, 23, 69.

30. Comroe, J. H., Jr., Dripps, R. D., Dumke, P. R., and Deming, M., Oxygen toxicity. The effect of inhalation of high concentrations of oxygen for 24 hours on normal men at sea level and at a simulated altitude of 18,000 feet. J. A. M. A., 1945, 128, 710.

31. Minot, G. R., Murphy, W. P., and Stetson, R. P., The response of the reticulocytes to liver therapy; particularly in pernicious anemia. Am. J. M. Sc., 1928, 175, 581.

32. Minot, G. R., Cohn, E. J., Murphy, W. P., and Lawson, H. A., Treatment of pernicious anemia with liver extract: Effects upon the production of immature and mature red blood cells. Am. J. M. Sc., 1928, 175, 599.

33. Strauss, M. B., Taylor, F. H. L., and Castle, W. B., Intramuscular use of liver extract: maximal responses of reticulocytes from daily intramuscular injection of extract derived from 10 grams of liver: Preliminary Communication. J. A. M. A., 1931, 97, 313. 
34. Heath, C. W., and Daland, G. A., The life of reticulocytes-experiments on their maturation. Arch. Int. Med., 1930, 46, 533.

35. Minot, G. R., and Castle, W. B., The interpretation of reticulocyte reactions: their value in determining the potency of therapeutic materials, especially in pernicious anemia. Lancet, 1935, 2, 319.

36. Bethell, F. H., The relation between the total reticulocyte production and the degree of bone marrow involvement in pernicious anemia. Am. J. M. Sc., 1934, 188, 476.

37. Koller, F., Uber die klinische Wirksamkeit hochkonzentrierter Leberextrakte. Deutsches Arch. f. klin. Med., 1938, 183, 296.

38. West, Randolph, Activity of vitamin $B_{12}$ in Addisonian pernicious anemia. Science, 1948, 107, 379.

39. Moore, C. V., Doan, C. A., and Arrowsmith, W. R., Studies in iron transportation and metabolism. II. The mechanism of iron transportation: its significance in iron utilization in anemic states of varied etiology. J. Clin. Invest., 1937, 16, 627.

40. Callender, S. T., Powell, E. O., and Witts, L. J., The life-span of the red cell in man. J. Path. \& Bact., 1945, 57, 129.

41. Shemin, D., and Rittenberg, D., The utilization of glycine for the synthesis of a porphyrin. J. Biol. Chem., 1945, 159, 567.

42. Comroe, J. H., Jr., and Dripps, R. D., Jr., Oxygen tension of arterial blood and alveolar air in normal human subjects. Am. J. Physiol., 1944, 142, 700.
43. Barcroft, J., Binger, C. A. S., Bock, A. V., Doggard, J. H., Forbes, H. S., Harrop, G., Meakins, J. C., and Redfield, A. C., Observations upon the effect of high altitude on the physiological processes of the human body, carried out in the Peruvian Andes chiefly at Cerro de Pasco. Phil. Tr. Roy. Soc. London, ser. B., 1923, 211, 351.

44. Hurtado, A., Merino, C., and Delgado, E., Influence of anoxemia on hemopoietic activity. Arch. Int. Med., 1945, 75, 284.

45. Kempner, W., The metabolism of human erythroblasts. J. Clin. Invest., 1936, 15, 679.

46. Rosin, A., and Rachmilewitz, M., Studies on bone marrow in vitro. III. The effect of anoxia and hyperoxia on explanted bone marrow. Blood, 1948, 3, 165.

47. Grant, W. C., and Root, W. S., Relation of oxygen in bone marrow blood to post-hemorrhagic erythropoiesis. Am. J. Physiol., 1947, 150, 618.

48. Berk, L., Burchenal, J. H., Wood, T., and Castle, W. B., Oxygen saturation of sternal marrow blood with special reference to pathogenesis of polycythemia vera. Proc. Soc. Exper. Biol. \& Med., 1948, 69, 316.

49. Ham, T. H., and Castle, W. B., (a) Personal communication. (b) Relation of increased hypotonic fragility and of erythrostasis to the mechanism of hemolysis in certain anemias. Tr. A. Am. Physicians, 1940, 55, 127. 